\title{
Editorial
}

\section{Academic Internationalization for Medical Education}

Academic internationalization is one of the most important drives in higher education in the 21 st century. In the context of medical education, in particular, internationalization gives us the opportunity to create a favourable learning environment that takes into account the global challenges health professionals must currently face.

The Faculty of Medicine of the University of São Paulo has thus accepted the challenge to foster internationalization, building upon existing initiatives of student and academic staff mobility and strengthening international academic and scientific collaboration with partner higher education institutions from different areas of the globe.

All our efforts are being taken, within the human rights and the medical ethics frameworks, with the belief that multicultural exchange is instrumental in providing a broader understanding of human diversity and of how the global epidemiology of disease is dependent on environmental, social and economic determinants of health.

To celebrate its centennial Revista de Medicina invited stakeholders from several leading Medical Schools in the world, including medical students and alumni, as well as distinguished academics to share their views and expertise about the importance of internationalization for Medical Education. Let their voices inspire and motivate us in medical skill building for the doctors we need in a globalized world.

\author{
Aluisio Cotrim Segurado \\ Professor of Infectious Diseases \\ President, International Relations Committee \\ Faculty of Medicine, University of São Paulo \\ Email: segurado@usp.br
}

